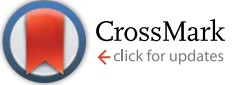

Cite this: RSC Adv., 2017, 7, 8694
Received 24th November 2016 Accepted 19th January 2017

DOI: $10.1039 / c 6 r a 27283 e$

rsc.li/rsc-advances

\section{A renewable bio-based epoxy resin with improved mechanical performance that can compete with DGEBA}

\author{
Saeid Nikafshar, ${ }^{a}$ Omid Zabihi, ${ }^{\text {tb }}$ Susan Hamidi, ${ }^{c}$ Yousef Moradi, ${ }^{\mathrm{d}}$ Saeed Barzegar, ${ }^{\mathrm{a}}$ \\ Mojtaba Ahmadie and Minoo Naebe ${ }^{\star b}$
}

The aim of this study is to find a suitable substitution for diglycidyl ether bisphenol A (DGEBA) to avoid the devastating side effects of bisphenol A. Vanillin, an aromatic compound, was used as a renewable material to synthesize a bio-based epoxy resin. The structure of the vanillin-based epoxy resin was confirmed by Fourier transform infrared spectroscopy (FT-IR) analysis. The major drawback of bio-based epoxy resins is their poor mechanical properties preventing them from competing with petroleum based epoxy resins such as DGEBA. Herein, a prepared calcium nitrate solution as an inorganic accelerator was used to accelerate the curing reaction of bio-based epoxy resin which reduced curing times as well as improving significantly the mechanical properties e.g., tensile strength, pull-off strength, and Izod impact strength. Differential scanning calorimetry (DSC) analysis was used to investigate the curing process and thermal properties of the vanillin-based epoxy resin with and without inorganic accelerators and also DGEBA without accelerators. The results showed that in the presence of $2 \mathrm{wt} \%$ inorganic accelerator, the initial onset curing temperature of vanillin-based epoxy resin was reduced from $60.1{ }^{\circ} \mathrm{C}$ to $8.5^{\circ} \mathrm{C}$, while the initial onset curing temperature of DGEBA was $55.8^{\circ} \mathrm{C}$. In addition, tensile strength and Izod impact strength of the vanillin-based epoxy system in the presence of inorganic accelerators increased in comparison to the DGEBA system. Moreover, in order to study the effect of inorganic accelerators on the toughness of the synthesized vanillin-based epoxy resin, fracture surfaces from Izod impact strength tests were observed using scanning electron microscopy (SEM) which confirmed improving mechanical properties.

\section{Introduction}

During recent years, bio-based polymers have attracted significant attention mainly due to the overuse of fossil fuels and reservoirs as well as the increase of greenhouse gas emission, causing serious environmental issues., ${ }^{\mathbf{1 , 2}}$ Bio-based polymers can be synthesized from renewable, inedible, and sustainable materials such as sucrose, ${ }^{3}$ lignin, ${ }^{4}$ and vegetable oils,,${ }^{5,6}$ which do not interfere with human and animal food.

DGEBA as an epoxy resin is one of the most used types of thermoset polymers due to its excellent chemical and mechanical properties. ${ }^{7,8}$ Thermoset polymers are widely

\footnotetext{
${ }^{a}$ Department of Applied Chemistry, Faculty of Chemistry, University of Tabriz, Tabriz, Iran

${ }^{b}$ Institute for Frontier Materials, Deakin University, Geelong, Victoria, Australia. E-mail: omid.zabihi@deakin.edu.au; Minoo.Naebe@deakin.edu.au; Tel: +61 469570372

${ }^{c}$ Applied Chemistry Research Laboratory, Department of Chemistry, Faculty of Science, University of Zanjan, Iran

${ }^{d}$ Department of Organic Chemistry, Faculty of Chemistry, Isfahan University of Technology, Isfahan, Iran

${ }^{e}$ Department of Chemical Engineering, Isfahan University of Technology, Isfahan, 84156/83111, Iran
}

utilized in a wide range of applications e.g., coatings, adhesives, and composites. ${ }^{\mathbf{9 - 1 1}}$ However, a significant AMOUNT of research and development is dedicated to replacing DGEBA with more environmentally friendly alternatives. ${ }^{11}$ This is because of the fact that more than $67 \%$ of the molar mass of DGEBA is strongly dependent on fossil sources. ${ }^{2}$ Moreover, bisphenol A (BPA) which is the raw material used in production of DGEBA has deleterious impacts on human health and environment, and it has also been proven that it can be toxic regarding living organisms and acts as an endocrine disruptor. ${ }^{12}$ Use of BPA in food packaging industry and food related materials has been forbidden in some countries such as Canada and France. ${ }^{\mathbf{1 3}}$ Therefore, in this regard, there have been substantial efforts concerning substituting bio-based and environmentally friendly materials with BPA. ${ }^{14}$

Epoxy resins can be synthesized from various types of biobased materials. Ferulic acid is a natural compound which is found in numerous inedible bio-resources like bagasse, wheat bran, beetroot pulp, and other bio-based diols under mild conditions. ${ }^{15}$ Currently, ferulic derivatives are used to synthesize copoly(ester-urethane)s, ${ }^{\mathbf{1 6}}$ isocyanate-based polyurethanes, ${ }^{17}$ and poly(anhydride-ester)s. ${ }^{18}$ Itaconic acid are also produced from fermentation carbohydrates such as glucose, 
which can be converted to epoxy resin by an esterification reaction. ${ }^{2}$ Eugenol, containing $70-90 \%$ clove oil, is another example for renewable phenol compounds, extracted form plants. Moreover, Wan et al. ${ }^{19}$ synthesized a high modulus and hardness, and low flammability bio-based epoxy resin form eugenol. Rosin is also a good candidate to synthesize bio-based epoxy resins because it consists of aromatic rings, expected to have high mechanical and thermal performances. ${ }^{20}$ Aouf et al. ${ }^{13}$ used gallic acid, which is a natural phenolic acid, to synthesize bio-based epoxy resin via a two-step synthesis rout in the presence of oxygen transfer agents. In another study, bio-based epoxy resins were synthesized from gallic and vanillic acids by chemo-enzymatic epoxidation with high degree of conversion to epoxides. ${ }^{14}$ Epoxidized soybean oil was also synthesized from vegetable oils and it was used as a thermosetting epoxy resin system. Since vegetable oils are aliphatic structures, epoxy resins based on epoxidized soybean oil have low thermal and mechanical properties. ${ }^{21}$ Among various sustainable and renewable materials, lignin has received much attention. After cellulose, lignin is the second most abundant natural material on earth. Lignin can be obtained from fibers of plants using various extraction methods. ${ }^{22}$ Aromatic groups of lignin potentially make it an ideal candidate for polymer synthesis. It is crystal clear that aromatic compounds have great thermal and mechanical properties, compared to aliphatic compounds. Lignin is a suitable natural material for obtaining low molar mass compounds like 4-hydroxy-3-methoxybenzaldehyde (vanillin) that could potentially be used in production of bioepoxy resins. It is extracted from lignin through various methods $^{22}$ in which approaches based on oxidation is set to result in a high yield. ${ }^{23,24}$ Although various compounds can be produced from lignin, vanillin is the most well-known valuable product. Vanillin is usually used as flavoring or chemical materials in pharmaceutical fields. ${ }^{25}$ But it can also be used as raw material to synthesize epoxy resin and the resulted epoxy resin from vanillin demonstrates good thermal and mechanical properties due to the presence of the aromatic ring in its structure. ${ }^{26,27}$ The chemical structures of lignin and vanillin are illustrated in Fig. 1.

The aim of this study is to synthesis a bio-based epoxy resin from vanillin and compare its thermal and mechanical properties with the DGEBA resin. An inorganic accelerator for curing process was also prepared to minimize the negative influence of low molecular weight of synthesized vanillin-based epoxy resin on its final performance. It is hypothesized that this inorganic accelerator affects mechanical performance of the epoxy matrix through inducing changes in physico-chemical events occurred during curing process. The goal is to develop a vanillin-based epoxy resin which gives the composites with competitive advantages over DGEBA as its rival.

\section{Experimental}

\section{Materials}

Liquid diglycidyl ether of bisphenol A (Epon 828), with epoxy equivalent weight of 185-192 eq. $\mathrm{g}^{-1}$ was supplied from E. V Roberts. Epikure F 205 was purchased from Hexion. Epikure F

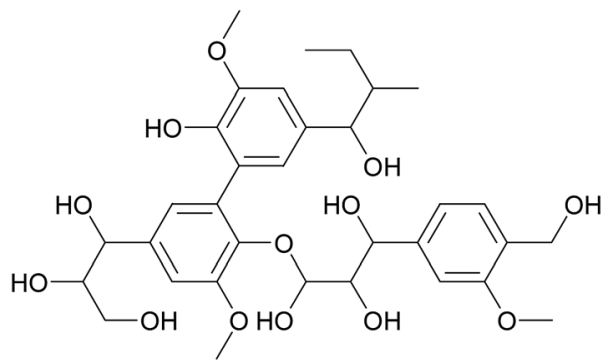

Lignin

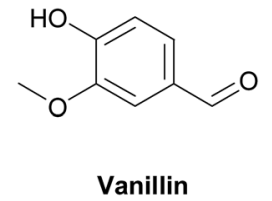

Fig. 1 Chemical structures of lignin and vanillin.

205 with amine equivalent weight of $105 \mathrm{~g}$ eq. ${ }^{-1}$ was utilized as a curing agent. Epichlorohydrin was supplied from Parachem. Vanillin (99\%), benzyltriethylammonium chloride (99\%), sodium hydroxide (97\%), ethyl acetate, sodium per carbonate, tetrahydrofuran, acetic acid, methanol, nitric acid (65\%), and calcium carbonate were purchased from Sigma Aldrich.

\section{Synthesis of vanillin-based epoxy resin}

To convert all aldehyde and ketone functional groups of vanillin to methoxyhydroquinone, Dakin oxidation was used according to the following steps: ${ }^{28}(1)$ vanillin $(1 \mathrm{~mol})$ and sodium percarbonate $(1 \mathrm{~mol})$ were dissolved in $100 \mathrm{ml}$ of tetrahydrofuran and $40 \mathrm{ml}$ distilled water in an ultrasonic bath for 15 min under argon atmosphere. Next, the reaction was quenched by addition of $10 \mathrm{ml}$ acetic acid and the total solution was concentrated by evaporating the solvent under vacuum until methoxyhydroquinone precipitation was obtained. (2) Methoxyhydroquinone $(1 \mathrm{~mol})$ and triethylbenzylammonium chloride $(1$

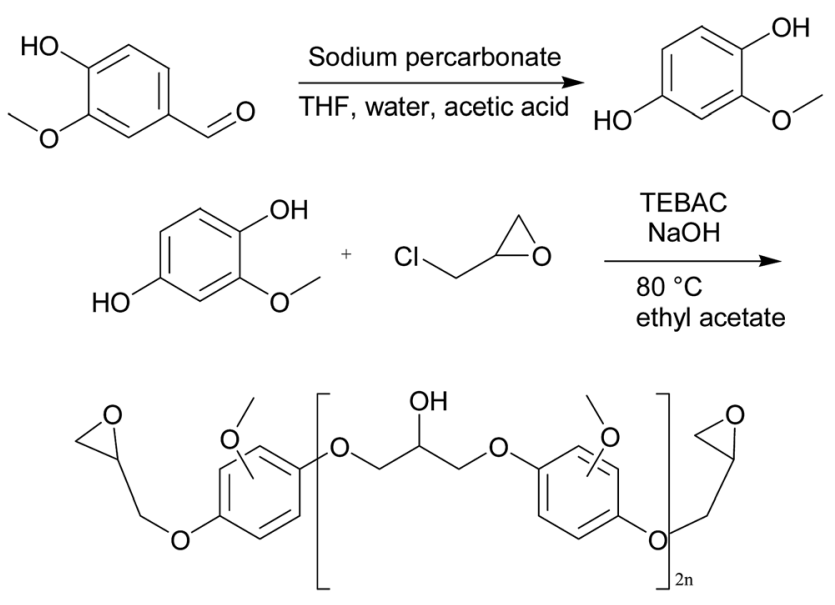

Fig. 2 Synthesis approach for bio-based epoxy resin from vanillin. 
Table 1 The fabricated epoxy systems with various compositions and their sample codes

\begin{tabular}{|c|c|c|c|c|}
\hline Sample code & Epoxy resin type & $\begin{array}{l}\text { Epoxy resin } \\
\text { amount }\end{array}$ & $\begin{array}{l}\text { Epikure F } 205 \\
\text { amount }\end{array}$ & $\begin{array}{l}\text { Wt } \% \text { inorganic } \\
\text { accelerator }\end{array}$ \\
\hline A & DGEBA & $100 \mathrm{~g}$ & $55.7 \mathrm{~g}$ & - \\
\hline $\mathrm{C}$ & Vanillin-based epoxy resin & $100 \mathrm{~g}$ & $42.4 \mathrm{~g}$ & $2 \%$ \\
\hline
\end{tabular}

mol) were poured into a flask and epichlorohydrin (10 mol) was charged into the flask. The resulting solution was mixed for $1 \mathrm{~h}$ at room temperature and $30 \mathrm{~min}$ at $80^{\circ} \mathrm{C}$. After cooling down to ambient temperature, $800 \mathrm{ml}$ of sodium hydroxide ( 5 molar) and triethylbenzylammonium chloride $(0.1 \mathrm{~mol})$ were added into the mixture and it was stirred for $30 \mathrm{~min}$ at $25{ }^{\circ} \mathrm{C}$. Afterwards, a twophased mixture of ethyl acetate/distilled water was added to the above mixture, followed by 5 min further stirring. The extraction was carried out two times in an aqueous phase with ethyl acetate. Organic phase containing vanillin-based epoxy resin was rinsed again with an aqueous solution of sodium chloride and dried over manganese sulfate. Excess of ethyl acetate and epichlorohydrin was eliminated using rotary evaporator. Silica gel flash chromatography was applied to purification using mixtures of cyclohexane/ethyl acetate. The chemical approach of vanillin-based epoxy resin synthesis is shown in Fig. 2.

\section{Synthesis of calcium nitrate as inorganic accelerator}

Calcium carbonate $(26.3 \mathrm{mmol})$ and $5.15 \mathrm{ml}$ of nitric acid $65 \%$ were stirred at room temperature for $2 \mathrm{~min}$. A green solution containing calcium nitrate was obtained. The reaction happened according to the following equation:

$$
\mathrm{CaCO}_{3}+4 \mathrm{HNO}_{3} \rightarrow \mathrm{Ca}\left(\mathrm{NO}_{3}\right)_{2}+\mathrm{CO}_{2}+\mathrm{H}_{2} \mathrm{O}+2 \mathrm{HNO}_{3}
$$

\section{Epoxy resin system preparation}

Firstly, the epoxy equivalent weight (EEW) of synthesized biobased resin was determined. For this propose, ASTM D1652 was used and its EEW was calculated to be 247.6 eq. $\mathrm{g}^{-1}$. The amine hydrogen molar mass (AHMM) of Epikure F 205 is $105 \mathrm{~g}$ eq. ${ }^{-1}$ and it is supposed that each amine hydrogen reacts with one epoxy group. Therefore, the stoichiometry ratio of epoxy resin and curing agent is calculated according to AHMM/EEW ratio. To prepare the samples, $100 \mathrm{~g}$ of epoxy resin was mixed with a calculated amount of Epikure F 205 as presented in Table 1. To make sure that all remaining liquids were removed from vanillin-based epoxy resin before adding curing agent, it was heated in silicon mold for $10 \mathrm{~min}$ at $120-130{ }^{\circ} \mathrm{C}$ before conducting curing process. After mixing all components for $30 \mathrm{~s}$ using a mechanical stirrer at a high speed stirring which was resulted in a uniform mixture, the curing process was accomplished in room temperature for 7 days.

\section{Measurements}

The FT-IR analysis was performed using a FT-IR spectrometer, Tensor 27, Burker with 40 scan average at a resolution of 4 $\mathrm{cm}^{-1}$. The DSC analysis was conducted using a Linseis, PT10, Germany to investigate the curing conditions and the reaction time. DSC instrument was firstly calibrated using standard zinc and indium, and $5 \mathrm{mg}$ of each prepared sample was used. As the curing reactions are started in room temperature in particular for the sample containing inorganic accelerator, after mixing the epoxy resin and curing agent with and without inorganic accelerator, the DSC tests should be done immediately on the mixtures. Non-isothermal DSC tests with a heating rate of $10{ }^{\circ} \mathrm{C}$ $\mathrm{min}^{-1}$ under nitrogen flow of $40 \mathrm{ml} \mathrm{min}^{-1}$ at temperature range between -50 to $170{ }^{\circ} \mathrm{C}$ were performed. To determine the glass transition temperature $\left(T_{\mathrm{g}}\right)$ of the fully-cured epoxy systems, a DSC scan was conducted on $5 \mathrm{mg}$ of each cured epoxy systems with a heating rate of $10{ }^{\circ} \mathrm{C} \min ^{-1}$ at the temperature range of

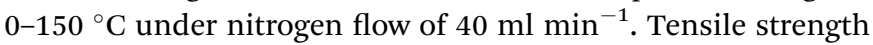
test was conducted in accordance with ASTM D638 by using Shimadzu 20KN-testing machine. Specimen dimensions of samples were selected according to type 1 of ASTM $(165 \times 19 \times$ $3.2 \mathrm{~mm})$. Crosshead speed was adjusted to be $2 \mathrm{~mm} \mathrm{~min}^{-1}$. At least five specimens were prepared and tested for each sample. The pull-off strength test was performed according to ASTM D4541 with a Posi Test AT-M from Deflesco. Each test was replicated five times on an aluminum surface. Izod impact strength was measured according to ASTM D256 by a Zwick/Roll 6103 impact tester at room temperature using specimens with dimensions of $63.5 \times 12.7 \times 7.2 \mathrm{~mm}$. For each sample, five replicates were performed. Fracture surfaces of the epoxy systems after Izod impact strength test were observed using SEM analyses by Tescan, MIRA3 FEG-SEM, Czech Republic at an accelerating voltage of $5.00 \mathrm{kV}$. Samples were coated with gold vapor to increase the resolution.

\section{Results and discussion}

\section{FTIR analysis}

To confirm the molecular structure of the synthesized vanillinbased epoxy resin, FT-IR spectroscopy was carried out in wavelengths of $3400-400 \mathrm{~cm}^{-1}$. The FT-IR spectrum of vanillin-based epoxy resin is shown in Fig. 3. The most important functional group of this compound, is the epoxy group which has an absorption peak in $915 \mathrm{~cm}^{-1}$, confirming the formation of epoxide rings. ${ }^{29}$ As can be seen in Fig. 3, the intensity of this peak is medium, due to the low amount of epoxy groups in the biobased resin. The absorption bond of $1185 \mathrm{~cm}^{-1}$ represents the presence of $\mathrm{C}-\mathrm{O}$ stretching of aromatic rings, ${ }^{30}$ and the peak around $3500 \mathrm{~cm}^{-1}$ indicates the hydroxyl groups of epoxy resin. Two absorption peaks at $2969 \mathrm{~cm}^{-1}$ and $2878 \mathrm{~cm}^{-1}$ are assigned to the stretching $\mathrm{CH}_{2}$ and $\mathrm{CH}$ of aromatic and aliphatic, 


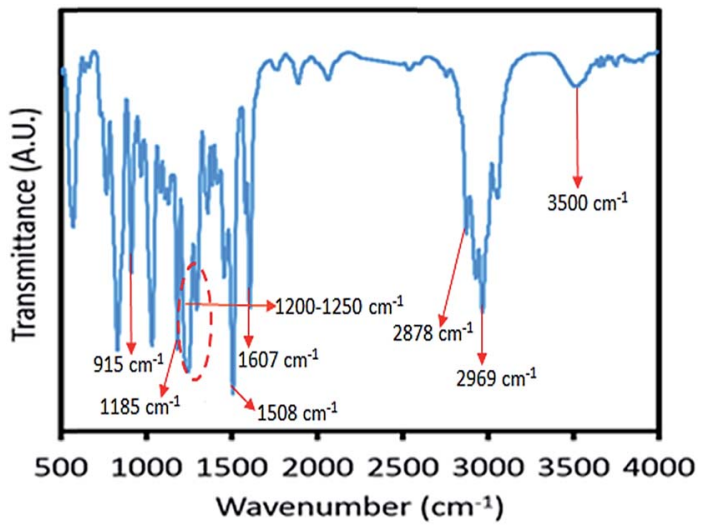

Fig. 3 FT-IR spectrum of synthesized vanillin-based epoxy resin.

respectively. ${ }^{31}$ Absorption peaks appeared at $1508-1607 \mathrm{~cm}^{-1}$ and $1200-1250 \mathrm{~cm}^{-1}$ are characteristic peaks of aromatic $\mathrm{C}=\mathrm{C}$ bonds and phenols $\mathrm{C}-\mathrm{O}$ groups, respectively. ${ }^{32}$ The peaks at 1035 and $831 \mathrm{~cm}^{-1}$ are also related to stretching $\mathrm{C}-\mathrm{O}-\mathrm{C}$ of ether and stretching $\mathrm{C}-\mathrm{O}-\mathrm{C}$ of oxirane groups, respectively. ${ }^{31}$ Moreover, vibration bond at $1458 \mathrm{~cm}^{-1}$ corresponds to methylene groups. ${ }^{33}$

\section{Epoxy matrix formation}

It has been frequently reported that bio-based epoxy resins cannot compete with DGEBA in terms of mechanical performance, in particular, regarding their brittleness due to the rigidity of benzene rings. ${ }^{34-36}$ To overcome this issue, an inorganic accelerator which affects curing process can be used that not only cures epoxy resins faster, but also improves mechanical properties of epoxy structure through changing the network architecture. In our previous study ${ }^{37}$ we have used a calcium nitrate solution as an accelerator which showed positive influence on the mechanical performance as well as curing time of DGEBA. It has been shown that DGEBA/Epikure F 205 system was cured only in $18 \mathrm{~min}$ at room temperature, whereas curing reaction without accelerator took more than $8 \mathrm{~h}$. Additionally, tensile strength, pull-off strength, and Izod impact strength for samples with the accelerator were enhanced by $17.7 \%, 19.1 \%$ and $44.7 \%$, respectively. ${ }^{37}$ Here, in order to reinforce the vanillin-based epoxy resin, the same inorganic accelerator was used to improve mechanical properties. In Fig. 4a, arrangements of epoxy structure with and without inorganic accelerator are compared. In the presence of inorganic accelerator, it is supposed that chains themselves align in a linear direction and such orientation helps mechanical properties to increase, whereas without inorganic accelerator polymeric chains do not have any specific direction.

DSC analyses provide information regarding formation of the epoxy matrix during the curing reaction, which can be useful to interpret the effect of accelerator on the matrix formation. ${ }^{\mathbf{8}, 38}$ Using DSC analysis, many studies have been conducted on thermal curing characteristics of various epoxy resin/curing agent systems. ${ }^{39,40}$ For sample A (DGEBA/Epikure F 205), the initial onset temperature $\left(T_{1}\right)$ is $55.8^{\circ} \mathrm{C}$ and first peak temperature $\left(T_{\mathrm{p} 1}\right)$ is $93.1{ }^{\circ} \mathrm{C}$, while non-isothermal DSC analysis for sample B (vanillin-based epoxy resin and Epikure $\mathrm{F}$ 205) shows that initial onset temperature $\left(T_{1}\right)$ and first peak temperature $\left(T_{\mathrm{p} 1}\right)$ are $60.1{ }^{\circ} \mathrm{C}$ and $97{ }^{\circ} \mathrm{C}$, respectively. $T_{1}$ and $T_{\mathrm{p} 1}$ of sample B are higher than those for sample A because the amount of epoxy groups in sample B are less than that in sample B. Comparison on the total heat of curing reaction $(\Delta H)$ of samples A and B confirms this claim since $\Delta H$ of sample $\mathrm{A}$ is higher than that of sample B. It is worth mentioning that opening of epoxy rings by amine groups is an exothermic reaction; therefore, the more epoxy groups are presented in structure, the higher the heat release is set to be. For sample $\mathrm{C}$ (vanillin-based epoxy resin, Epikure F 205 and 2 wt\% inorganic accelerator), the curing process of epoxy resin is divided into two steps. In the first step, as presented in Table $2, T_{1}$ and $T_{\mathrm{p} 1}$
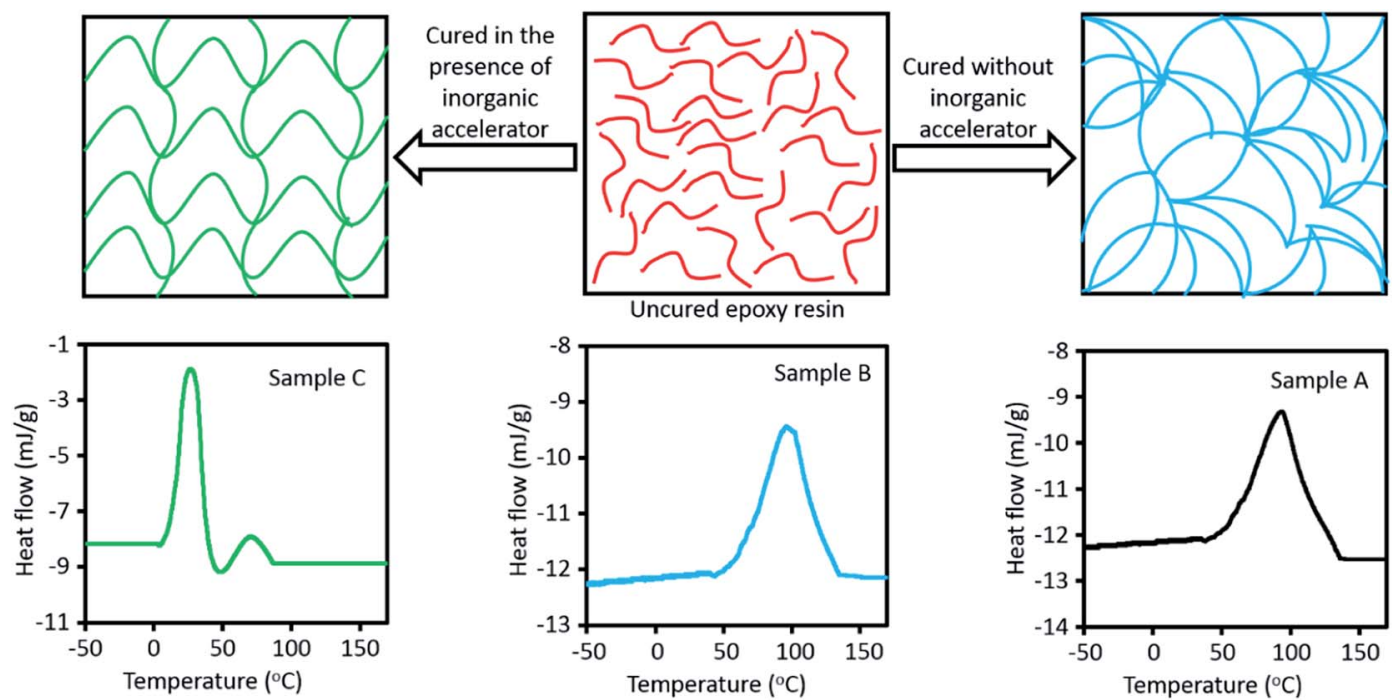

Fig. 4 Comparison of arrangement of epoxy structure with and without inorganic accelerator (top), and heat flow versus temperature obtained for the various samples at heating rate of $10{ }^{\circ} \mathrm{C} \mathrm{min}^{-1}$ (bottom). 
Table 2 Thermal characteristics of curing process of the various samples obtained from DSC analyses at heating rate of $10{ }^{\circ} \mathrm{C} \mathrm{min}-1$

\begin{tabular}{lclllc}
\hline Sample code & $T_{1}\left({ }^{\circ} \mathrm{C}\right)$ & $T_{\mathrm{p} 1}\left({ }^{\circ} \mathrm{C}\right)$ & $T_{2}\left({ }^{\circ} \mathrm{C}\right)$ & $T_{\mathrm{p} 2}\left({ }^{\circ} \mathrm{C}\right)$ & $\Delta H\left(\mathrm{~J} \mathrm{~g}^{-1}\right)$ \\
\hline A & 55.8 & 93.1 & - & - & 56.97 \\
B & 60.1 & 97 & - & - & 52.38 \\
C & 8.5 & 26.65 & 50.1 & 71.2 & 216.39
\end{tabular}

are $8.5{ }^{\circ} \mathrm{C}$ and $26.65{ }^{\circ} \mathrm{C}$, respectively, which means that curing reaction started much earlier in the presence of inorganic accelerator, compared with $T_{1}$ and $T_{\mathrm{p} 1}$ of samples A and B. As presented in Table 2, for the second step, second onset temperature $\left(T_{2}\right)$ and second temperature peak $\left(T_{\mathrm{p} 2}\right)$ are $50.1^{\circ} \mathrm{C}$ and $71.2{ }^{\circ} \mathrm{C}$, correspondingly. It is assumed that at the beginning of curing reaction, inorganic accelerator expedited curing reactions, but its amount is not sufficient and curing reactions remain incomplete. Then the temperature should increase until it reaches the second step, and curing reactions are terminated at this stage. It should be mentioned that even second part of curing process of sample $\mathrm{C}$ is faster than sample B. Although inorganic accelerator was consumed totally, since inorganic accelerator generated heat in epoxy system, it is usual that with increasing temperature of epoxy system, curing reaction is done faster. In the section one, inorganic accelerator released heat during curing reaction, and after that the temperature of system increased and it is logical that after consuming inorganic accelerator, second section was completed in a lower temperature, compared with sample B. The $\Delta H$ of sample $\mathrm{C}$ is much higher (about four times more than $\Delta H$ samples $\mathrm{A}$ and $\mathrm{B}$ ), demonstrating that inorganic accelerator has an effective role in heat creation during curing reaction.

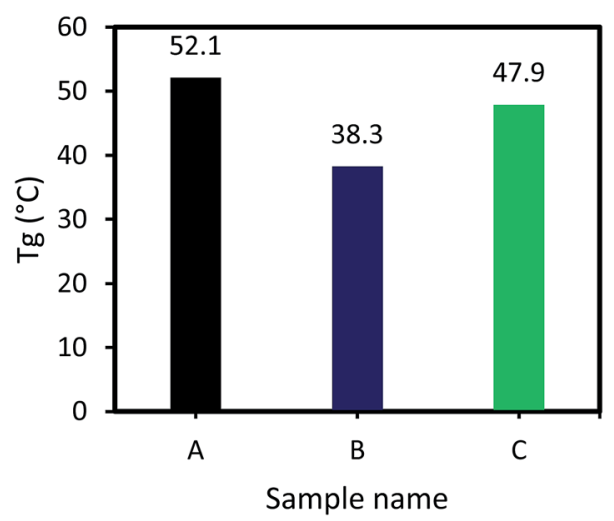

Fig. $5 T_{\mathrm{g}}$ values of the various samples obtained by DSC analyses.
As illustrated in Fig. 5, $T_{\mathrm{g}}$ of sample A (DGEBA and F 205) is higher than that of the sample $B$ (vanillin-based epoxy resin and $\mathrm{F}$ 205). It is clear that the number of epoxy groups in DGEBA is higher, compared to the vanillin-based epoxy resin. If the number of epoxy groups is higher, more amount of curing agent for curing reaction needs. For curing of $100 \mathrm{~g}$ DGEBA, 55.7 Epikure F 205 is required, while for curing $100 \mathrm{~g}$ of vanillinbased epoxy resin, $42.5 \mathrm{~g}$ Epikure F 205 is required. According to this comparison, DGEBA has more epoxy groups than vanillinbased epoxy resin. As can be seen, $T_{\mathrm{g}}$ of sample $\mathrm{A}$ is higher than sample B, indicating higher crosslink density in sample A. ${ }^{20}$ As the heat of reaction for sample A is higher than that of sample B, it can form an epoxy matrix with higher $T_{\mathrm{g}}$. As shown in Fig. 5, addition of $2 \mathrm{wt} \%$ inorganic accelerators increased $T_{\mathrm{g}}$ of vanillinbased epoxy sample from $38.3^{\circ} \mathrm{C}$ to $47.9^{\circ} \mathrm{C}$. This increment in $T_{\mathrm{g}}$ is in agreement with its higher heat of reaction which can also increase crosslink density of the epoxy matrix and consequently improves its $T_{\mathrm{g} .}{ }^{41}$ It can be also said that the inorganic salt formed during curing reaction can act as a filler in reinforcement of epoxy matrix, resulting in an increase in $T_{\mathrm{g}}$ due to the more effective stress transfer from matrix to the inorganic salt. It is reported that when inorganic nanoparticles are added into various types of polymers, $T_{\mathrm{g}}$ is about to increase. This is due to the fact that nanoparticles occupy distances between polymers chains, leading to restriction of polymer chains mobility. ${ }^{\mathbf{4 2 - 4 5}}$ The values of $T_{\mathrm{g}}$ for three samples are illustrated in Fig. 5.

\section{Mechanical performance}

According to Table 3, tensile strength and elongation at break of sample A are higher than those of samples B. This can be attributed to the more available epoxy groups in sample A which can produce a better epoxy network with high tensile properties. In order to improve the tensile strength in synthesized vanillinbased epoxy resin, the inorganic accelerator was used. Using this accelerator, the architecture of cured epoxy was changed and its configuration becomes almost parallel to each other. In other words, the polymer chains were oriented in a linear direction, which resulted in enhanced tensile strength and elongation at break for sample C. In our previous work, ${ }^{37}$ it was confirmed that by using this inorganic accelerator, the length of polymer chains increased. According to the proposed mechanism, cationic or anionic polymerization occurred and epoxy chains grow more in the length direction. ${ }^{\mathbf{4 6 , 4 7}}$ As such, the tensile strength of sample $\mathrm{C}$ became higher than that of sample A. Tensile strength of sample $C$ is $3.21 \%$ and $105.97 \%$ higher than of samples A and B, respectively. It means that tensile strength of vanillin-based epoxy not only was doubled as result

Table 3 Tensile strength, tensile modulus and elongation at break of the various samples

\begin{tabular}{|c|c|c|c|c|}
\hline A & $29.63 \pm 1.3$ & $1770.88 \pm 46.4$ & $1.79 \pm 0.41$ & $4.41 \pm 0.3$ \\
\hline $\mathrm{C}$ & $30.58 \pm 1.7$ & $959.11 \pm 27.6$ & $1.72 \pm 0.89$ & $3.71 \pm 0.2$ \\
\hline
\end{tabular}




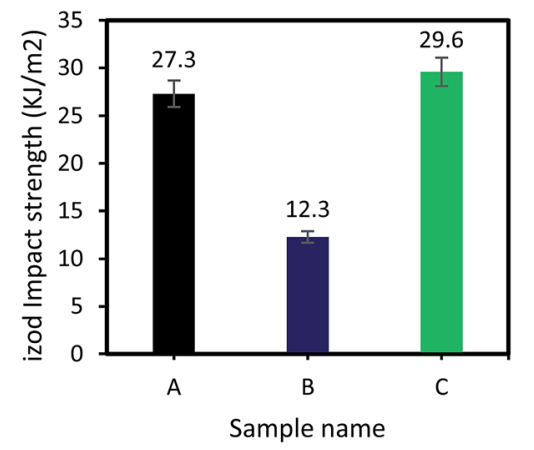

Fig. 6 Impact Izod strength of various samples.

of addition of inorganic accelerator, but also it reached to a higher tensile strength compared to the DGEBA based epoxy system. As can be seen, elongation at break of sample C is $4.07 \%$ lower than that of sample A which may be due to formation of inorganic salt during curing reaction.

According to the results presented in Table 3, pull-off strength of sample A is also $\sim 221 \%$ higher than that of sample B, which means a weak coating adhesion in sample B. However, in sample C, pull-off strength only $\sim 18 \%$ is lower than that of sample $\mathrm{A}$, which indicates that inorganic accelerator enhanced considerably pull-off strength of vanillin-based epoxy system. In other words, pull-off strength of sample C is $\sim 170 \%$ higher than that of sample $\mathrm{B}$ and this comparison proves positive effect of inorganic accelerator on pull-off strength of epoxy system. There are several investigations already confirming that the presence of inorganic fillers in epoxy matrix can improve pull-off strength adhesion. ${ }^{48,49}$
The Izod impact strength of the epoxy systems was also investigated and results are presented in Fig. 6. As shown, impact Izod strength of sample B (vanillin-based epoxy resin) is $\sim 50 \%$ lower than that of the sample A (DGEBA), whereas it significantly increases for the vanillin-based epoxy sample containing $2 \mathrm{wt} \%$ inorganic accelerator. Izod impact strength of sample C increases up to $29.6 \mathrm{~kJ} \mathrm{~m}^{-2}$ which is $8.5 \%$ higher than that of the sample A. The inorganic salt fills the gap in epoxy matrix and assists in absorbing energy from impact. This can be further investigated through SEM observations on the fracture surface of samples after Izod impact tests.

\section{Morphological observations}

As illustrated in SEM micrographs presented in Fig. 7, the fracture surface of sample A is smooth and ridges and nodes can be seen on entire fracture surface. Fracture surface of sample B is fairly flat and smooth confirming a clean and fairly easy break which is in agreement with mechanical performance observed. On the other hand, SEM image of sample C shows a completely jagged and rough surface. The jagged surface absorbs more energy and it goes without saying that sample $\mathrm{C}$ needs more energy and force to be break. ${ }^{50}$ It is hypothesized that the inorganic salt acts like a force absorber and that the accelerator improves sample toughness. Thus in the presence of inorganic accelerator, vanillin-based epoxy resin has higher toughness even more than that of DGEBA.

\section{Conclusion}

We synthesized a renewable bio-based epoxy resin from vanillin and its chemical structure was successfully confirmed by FTIR

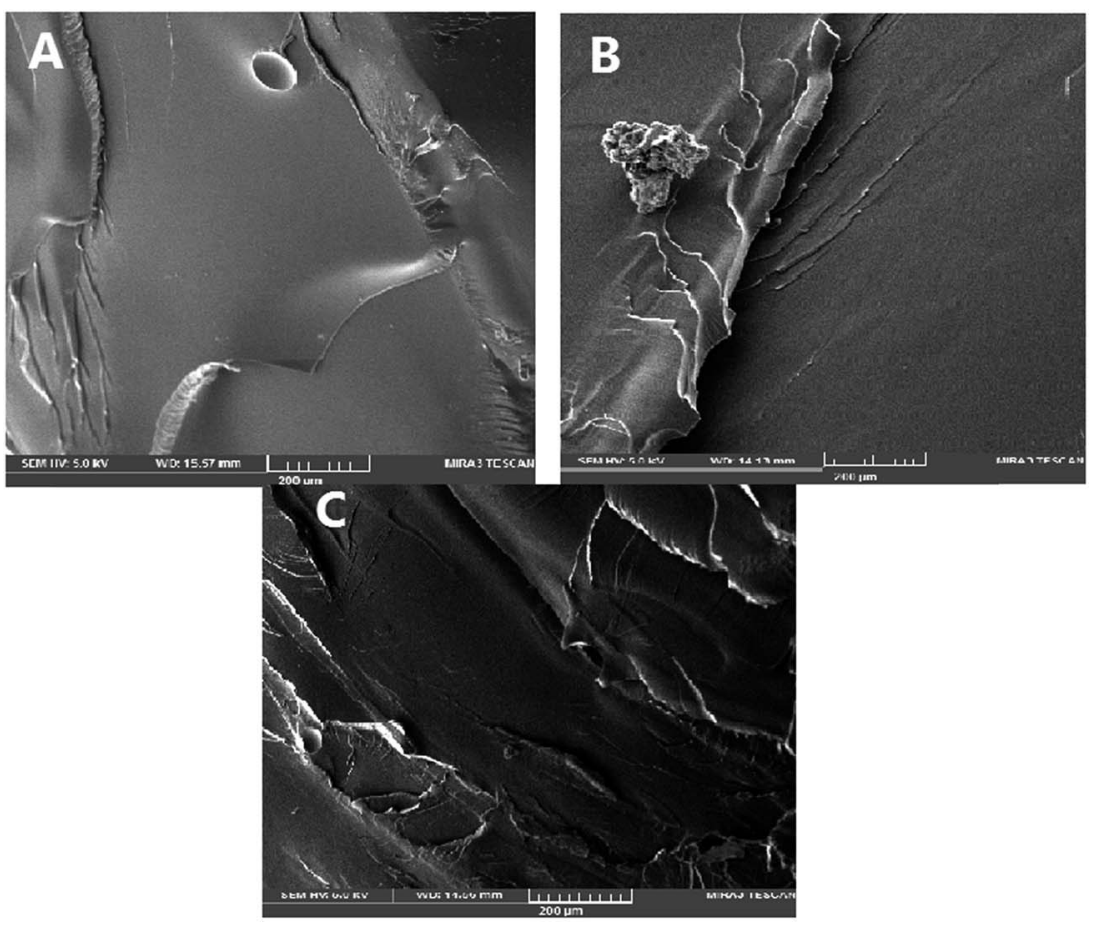

Fig. 7 SEM images of the fractured surfaces of the various samples. 
analysis. The mechanical properties of the synthesized vanillinbased epoxy resin were enhanced and the curing reaction of vanillin-based epoxy resin with Epikure F 205 as hardener was accelerated by using calcium nitrate solution as accelerator. Using $2 \mathrm{wt} \%$ inorganic accelerator in vanillin-based system, initial onset temperature and temperature peak decreased dramatically which means an efficient curing process for biobased epoxy matrix. The effects of inorganic accelerator on curing reaction of epoxy resin were not limited only to thermal properties. The results of mechanical properties of vanillinbased epoxy resin including $2 \mathrm{wt} \%$ inorganic accelerator illustrated that tensile strength and Izod impact strength were higher than those for DGEBA system, which was confirmed by SEM observations. It was found that enhancements of $\sim 3 \%$ and $\sim 8 \%$ in tensile strength and impact Izod strength of vanillinbased epoxy resin can be achieved, respectively, in comparison to the DGEBA system, which can compete comparatively with DGEBA system. Meanwhile, other mechanical properties remain also quite comparable with DGEBA system. It is believed that this new vanillin-based epoxy resin with inorganic accelerator will pave the way for development of high performance epoxy resin systems from renewable resources.

\section{Notes and references}

1 S. Benyahya, C. Aouf, S. Caillol, B. Boutevin, J. P. Pascault and H. Fulcrand, Ind. Crops Prod., 2014, 53, 296-307.

2 S. Ma, X. Liu, Y. Jiang, Z. Tang, C. Zhang and J. Zhu, Green Chem., 2013, 15, 245-254.

3 X. Feng, A. J. East, W. B. Hammond, Y. Zhang and M. Jaffe, Polym. Adv. Technol., 2011, 22, 139-150.

4 F. Ferdosian, Z. Yuan, M. Anderson and C. Xu, RSC Adv., 2014, 4, 31745-31753.

5 S. G. Tan and W. S. Chow, J. Therm. Anal. Calorim., 2010, 101, 1051-1058.

6 J. Zhu, K. Chandrashekhara, V. Flanigan and S. Kapila, J. Appl. Polym. Sci., 2004, 91, 3513-3518.

7 D. S. Achilias, M. M. Karabela, E. A. Varkopoulou and I. D. Sideridou, J. Macromol. Sci., Part A: Pure Appl. Chem., 2012, 49, 630-638.

8 O. Zabihi, Thermochim. Acta, 2012, 543, 239-245.

9 A. Mirmohseni and S. Zavareh, Mater. Des., 2010, 31, 26992706.

10 O. Zabihi, H. Khayyam, B. L. Fox and M. Naebe, New J. Chem., 2015, 39, 2269-2278.

11 O. Zabihi, M. Ahmadi, H. Khayyam and M. Naebe, Sci. Rep., 2016, 6, 38194.

12 S. Flint, T. Markle, S. Thompson and E. Wallace, J. Environ. Manage., 2012, 104, 19-34.

13 C. Aouf, H. Nouailhas, M. Fache, S. Caillol, B. Boutevin and H. Fulcrand, Eur. Polym. J., 2013, 49, 1185-1195.

14 C. Aouf, J. Lecomte, P. Villeneuve, E. Dubreucq and H. Fulcrand, Green Chem., 2012, 14, 2328-2336.

15 R. Ménard, S. Caillol and F. Allais, Ind. Crops Prod., 2017, 95, 83-95.

16 F. Pion, A. F. Reano, M. Z. Oulame, I. Barbara, A. L. Flourat, P.-H. Ducrot and F. Allais, in Green Polymer Chemistry:
Biobased Materials and Biocatalysis, American Chemical Society, 2015, vol. 1192, ch. 4, pp. 41-68.

17 M. A. Ouimet, J. J. Faig, W. Yu and K. E. Uhrich, Biomacromolecules, 2015, 16, 2911-2919.

18 M. Z. Oulame, F. Pion, S. Allauddin, K. V. S. N. Raju, P.-H. Ducrot and F. Allais, Eur. Polym. J., 2015, 63, 186-193.

19 J. Wan, B. Gan, C. Li, J. Molina-Aldareguia, E. N. Kalali, X. Wang and D.-Y. Wang, Chem. Eng. J., 2016, 284, 10801093.

20 X. Liu, W. Huang, Y. Jiang, J. Zhu and C. Zhang, eXPRESS Polym. Lett., 2012, 6, 293-298.

21 A. Gupta, S. Ahmad and A. Dev, Polym.-Plast. Technol. Eng., 2010, 49, 657-661.

22 S. Laurichesse and L. Avérous, Prog. Polym. Sci., 2014, 39, 1266-1290.

23 J. D. Araújo, C. A. Grande and A. E. Rodrigues, Chem. Eng. Res. Des., 2010, 88, 1024-1032.

24 J. C. Villar, A. Caperos and F. García-Ochoa, Wood Sci. Technol., 2001, 35, 245-255.

25 E. B. da Silva, M. Zabkova, J. Araújo, C. Cateto, M. Barreiro, M. Belgacem and A. Rodrigues, Chem. Eng. Res. Des., 2009, 87, 1276-1292.

26 J. F. Stanzione Iii, J. M. Sadler, J. J. La Scala, K. H. Reno and R. P. Wool, Green Chem., 2012, 14, 2346-2352.

27 M. Fache, E. Darroman, V. Besse, R. Auvergne, S. Caillol and B. Boutevin, Green Chem., 2014, 16, 1987-1998.

28 G. Kabalka, N. Reddy and C. Narayana, Tetrahedron Lett., 1992, 33, 865-866.

29 A. Rigail-Cedeño and C. S. P. Sung, Polymer, 2005, 46, 93789384.

30 R. Thomas, S. Durix, C. Sinturel, T. Omonov, S. Goossens, G. Groeninckx, P. Moldenaers and S. Thomas, Polymer, 2007, 48, 1695-1710.

31 M. G. González, J. Baselga and J. C. Cabanelas, Applications of FTIR on epoxy resins-identification, monitoring the curing process, phase separation and water uptake, INTECH Open Access Publisher, 2012.

32 J. Canavate, X. Colom, P. Pages and F. Carrasco, Polym.-Plast. Technol. Eng., 2000, 39, 937-943.

33 D. L. Pavia, G. M. Lampman, G. S. Kriz and J. A. Vyvyan, Introduction to spectroscopy, Cengage Learning, 2008.

34 G. Mashouf Roudsari, M. Misra and A. K. Mohanty, J. Appl. Polym. Sci., 2017, 134, 44352-44361.

35 M. Stemmelen, F. Pessel, V. Lapinte, S. Caillol, J. P. Habas and J. J. Robin, J. Polym. Sci., Part A: Polym. Chem., 2011, 49, 2434-2444.

36 J. M. España, L. Sánchez-Nacher, T. Boronat, V. Fombuena and R. Balart, J. Am. Oil Chem. Soc., 2012, 89, 2067-2075.

37 A. Mirmohseni-Namin, S. Nikafshar and F. Mirmohseni, RSC Adv. , 2015, 5, 53025-53035.

38 R. Thomas, S. Durix, C. Sinturel, T. Omonov, S. Goossens, G. Groeninckx, P. Moldenaers and S. Thomas, Polymer, 2007, 48, 1695-1710.

39 X. D. Liu, A. Sudo and T. Endo, J. Polym. Sci., Part A: Polym. Chem., 2011, 49, 250-256.

40 S.-G. Hong and C.-S. Wu, Thermochim. Acta, 1998, 316, 167175. 
41 V. B. Gupta, L. T. Drzal, C. Y. C. Lee and M. J. Rich, Polym. Eng. Sci., 1985, 25, 812-823.

42 C.-C. Wu and S. L.-C. Hsu, J. Phys. Chem. C, 2010, 114, 21792183.

43 T. S. Radoman, J. V. Džunuzović, K. B. Jeremić, B. N. Grgur, D. S. Miličević, I. G. Popović and E. S. Džunuzović, Mater. Des., 2014, 62, 158-167.

44 O. Zabihi, M. Aghaie and K. Zare, J. Therm. Anal. Calorim., 2013, 111, 703-710.

45 O. Zabihi, M. Ahmadi, M. Akhlaghi bagherjeri and M. Naebe, RSC Adv., 2015, 5, 98692-98699.
46 A. Dworak, W. Walach and B. Trzebicka, Macromol. Chem. Phys., 1995, 196, 1963-1970.

47 S. Mortimer, A. Ryan and J. Stanford, Macromolecules, 2001, 34, 2973-2980.

48 S. Sabagh, A. R. Bahramian and M. Kokabi, Iran. Polym. J., 2012, 21, 229-237.

49 P. Carballeira and F. Haupert, Polym. Compos., 2010, 31, 1241-1246.

50 O. Zabihi, Composites, Part B, 2013, 45, 1480-1485. 